\title{
EDITORIAL
}

For reprint orders, please contact: reprints@futuremedicine.com

\section{Songs for silent suffering: could music help with postsurgical pain?}

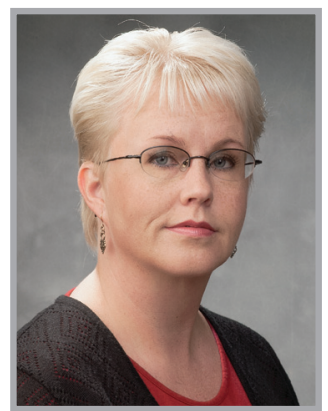

Päivi Kankkunen*1

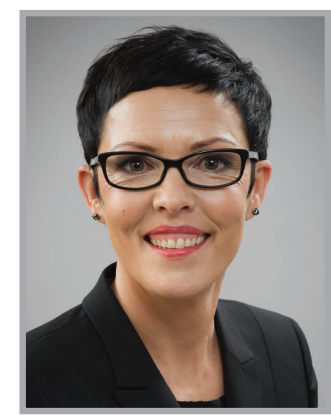

Anne Vaajoki ${ }^{1}$

\author{
"Listening to music to \\ reduce patients' mild or \\ moderate postoperative pain \\ is an easy intervention and \\ has no adverse effects."
}

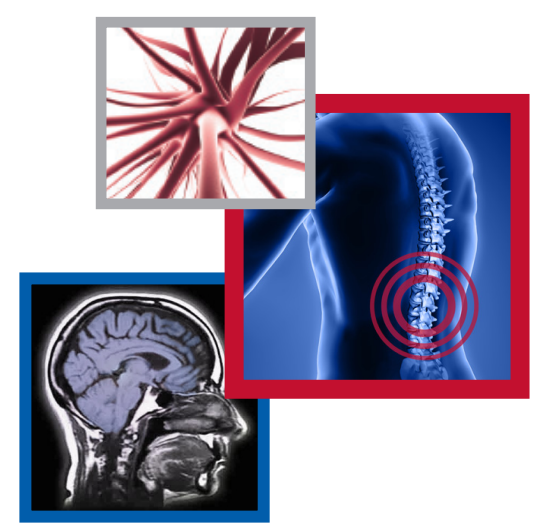

Despite a fairly long tradition of research focusing on pain, recent studies have shown that patient experiences of moderate-to-severe pain are common after surgery [1], and postsurgical pain remains poorly managed [2]. Adjuvant to analgesics, nonpharmacological methods, such as music, can be implemented to alleviate postsurgical pain. It has been stated that a combination of analgesics and music provide improved pain alleviation of up to $23 \%$ [3], and this might be one option for preventing chronic pain development.

Pain is a complex and always subjective experience that includes physiological, sensory, emotional, cognitive, behavioral and sociocultural components $[4,5]$. If we properly apply this definition of pain as defined above, we must also manage patients' pain in a multidimensional way, not only from the point of view of the intensity of pain, but also alleviate distress caused by pain. Music interventions can be used by passively listening to prerecorded music via headphones provided by nursing personnel (music medicine) or as controlled procedures in which patients' psychological and physiological entities must be considered in relation to sound, rhythm, melody, harmony and tempo. Music can be played actively or passively (music therapy). In this article, we will focus on listening to music as a nursing intervention in pain alleviation in postsurgical patients [6].

The effectiveness of music on pain after surgery has been increasingly investigated during recent years in many patient groups and settings. The effects of music on pain have been tested among infants [7], adolescents [8], adults $[9,10]$ and the elderly [11]. Listening to music to reduce patients' mild or moderate postoperative pain is an easy intervention and has no adverse effects [12]. It has been established that listening to music after surgery could spare the use of analgesia and limit its adverse effects. Additionally, music triggers positive physiological responses, such as reduced blood pressure and respiratory rates $[9,13]$. For patients, music provides a healing environment, enhances the quality of their hospital stay and is an integral part of the multimodal regimen administered to patients undergoing surgery [6,14]. In addition, music is found to decrease the severity of postoperative delirium [15].

There are no guidelines for listening to music or administering music therapy. Despite the many positive effects of listening to music, it is possible that it could

'Department of Nursing Science, University of Eastern Finland, PO Box 1627, FIN-70211 Kuopio, Finland *Author for correspondence: Tel.: +35 840821 1984; paivi.kankkunen@uef.fi

\footnotetext{
"Music interventions can be used

by passively listening to

prerecorded music via

headphones provided by nursing personnel (music medicine) or as controlled procedures in which patients' psychological and physiological entities must be considered in relation to sound,

rhythm, melody, harmony and tempo."
} 
irritate the patient, particularly if it is not the kind of music preferred by the patient $[3,16,17]$. There are also patients who do not like listening to music at all or for whom music has no meaning [18]. Music has also been reported to disturb communication between anesthesiologists and patients during surgery [13], and it is possible that music may disturb some patients at wards during postoperative phases. Therefore, patients should have the opportunity to listen to music via personal headphones, or a music pillow in order to avoid unnecessary noises in the room and to prevent hospital infections from spreading via headphones.

Research results are contradictory on the effects of listening to music owing to methodological limitations. The main reasons include small sample sizes, nonobjective outcome measures and nonvalidated instruments. Due to the nature of music interventions, participants are usually aware of their position in the music or control group and blinding them is more difficult [19]. There are different views on the optimal time for listening to music and whether patient-selected music or research-selected music is more beneficial. The long-term effects of listening to music are still unknown. Poor music intervention study results may have been caused by the fact that the parameters used have not been the most adequate to evaluate the effects of listening to music.

In most of the studies, cultural issues connected to music preferences are not taken into account. However, it is important for patients to have information about listening to music for pain alleviation before surgery and for the music selection to take into account the patient's age, culture and familiarity with music [12]. Classical music may be most suitable in acute situations, but some patients benefit from, for example, sounds of the Quran [20]. Therefore, it is important to be aware of the patient's cultural background and how it is related to the preferred music.

In conclusion, the effects of music have often been investigated by using randomized controlled trial designs and the available evidence varies between weak and moderate. In the future, in research fields in addition to physiological parameters, we have to pay more attention to patients' own experiences and personal reports about their experiences of listening to music as a part of an impact study. Despite an increased number of quantitative studies, we also need qualitative research to investigate the effectiveness of music on surgical pain as experienced by patients. We must ask whether it is possible to measure patients' pain and experiences of listening to music only by using numbers. Additionally, more research is needed to provide information of the most suitable types of music and the frequency of listening to it. In nursing practice, we need to be more aware of nonpharmacological pain management methods that can diversify the treatment of pain and are an important supplement to analgesia treatment after surgery.

Financial \& competing interests disclosure The authors have no relevant affiliations or financial involvement with any organization or entity with a financial interest in or financial conflict with the subject matter or materials discussed in the manuscript. This includes employment, consultancies, honoraria, stock ownership or options, expert testimony, grants or patents received or pending, or royalties.

No writing assistance was utilized in the production of this manuscript.

\section{References}

1 Lahtinen P. Pain after coronary artery bypass grafting surgery: clinical studies of acute and persistent postoperative pain. In: Dissertations in Health Sciences. Publications of the University of Eastern Finland, Kuopio, Finland, 126 (2012).

2 Good M, Albert J, Anderson G et al. Supplementing relaxation and music for pain after surgery. Nurs. Res. 59(4), 259-269 (2010).

3 Jafari H, Zeydi A, Khani S, Esmaeili R, Soleimani A. The effects of listening to preferred music on pain intensity after open heart surgery. Iran. J. Nurs. Midwifery Res. 17(1), 1-6 (2012).
4 Pain terms: a list of definitions and note on usage. Recommended by the IASP

Subcommittee on Taxonomy. Pain 6(3), 249 (1979).

5 McCaffery M. Nursing Management of the Patient with Pain. JP Lippincott, PA, USA (1979).

6 Gooding L, Swezey S, Zwischenberger JB. Using music interventions in perioperative care. South. Med. J. 105(9), 486-490 (2012).

7 Bellieni C, Alagna M, Buonocore G. Analgesia for infants' circumcision. Ital. J. Pediatr. 39, 38 (2013).

8 Kleiber C, Adamek MS. Adolescents' perceptions of music therapy following spinal fusion surgery. J. Clin. Nurs. 22, 414-422 (2012).

9 Vaajoki A, Kankkunen P, Pietilä AM, Vehviläinen-Julkunen K. Music as a nursing intervention: effects of music listening on blood pressure, heart rate, and respiratory rate in abdominal surgery patients. Nurs. Health Sci. 13, 412-418 (2011).

10 Angioli R, De Cicco Nardone C, Plotti F et al. The use of music to reduce anxiety during office hysteroscopy: a prospective randomized trial. J. Minim. Invasive Gynecol. doi:10.1016/j.jmig.2013.07.020 (2013) (Epub ahead of print).

11 Rantala M, Kankkunen P, Kvist T, Hartikainen S. Post-operative pain 
management practices in patients with dementia - the current situation in Finland. Open Nurs. J. 6, 72-82 (2012).

12 Matsota P, Christodoulopoulou T, Smurnioti ME et al. Music's use for anesthesia and analgesia. J. Altern. Complement. Med. 19(4), 298-307 (2013).

13 Moris D, Linos D. Music meets surgery: two sides to the art of 'healing'. Surg. Endosc. J. 27, 719-723 (2013).

14 Vaajoki A, Kankkunen P, Pietilä AM, Kokki $\mathrm{H}$, Vehviläinen-Julkunen $\mathrm{K}$. The impact of listening to music on analgesic use and length of hospital stay while recovering from laparotomy. Gastroenter. Nurs. 35(4), 279-284 (2012).
15 McCaffery R. The effect of music on acute confusion in older adults after hip or knee surgery. Appl. Nurs. Res. 22, 107-112 (2009).

16 Gravesen M, Sommet T. Perioperative music may reduce pain and fatigue in patients undergoing laparoscopic cholecystectomy. Acta Anaestehsiol. Scand. 57, 1010-1016 (2013).

17 Bernazky G, Prech M, Anderson M, Panksepp J. Emotional foundations of music as a non-pharmacolgical pain management tool in modern medicine. Neurosci. Biobehav. Rev. 35, 1989-1999 (2011).

18 Vaajoki A, Pietilä AM, Kankkunen P, Vehviläinen-Julkunen K. Music intervention study in abdominal surgery patients: challenges of an intervention study in clinical practice. Int. J. Nurs. Pract. 19, 206-213 (2013).

19 Polit DF, Gillespie BM, Griffin R. Deliberate ignorance. A systematic review of blinding in nursing clinical trials. Nurs. Res. 60, 9-16 (2011).

20 Allameh T, Jabalalemi M, Lorestani K, Akbari M. The efficacy of Quran sound on anxiety and pain of patients under cesarean section with regional anesthesia: a randomized case-controlled clinical trial. J. Isfahan Med. School31(235), 601-610 (2013). 